\title{
Availability and affordability of priority life- saving medicines for under-five children in health facilities of Tigray region, northern Ethiopia
}

Solomon Abrha ${ }^{1 *}$, Ebisa Tadesse ${ }^{1}$, Tesfay Mehari Atey ${ }^{2}$, Fantahun Molla', Wondim Melkam4, Birhanetensay Masresha ${ }^{3}$, Solomon Gashaw ${ }^{1}$ and Abrham Wondimu'

\begin{abstract}
Background: In developing countries, child health outcomes are influenced by the non-availability of priority lifesaving medicines at public sector health facilities and non-affordability of medicines at private medicine outlets. This study aimed to assess availability, price components and affordability of priority life-saving medicines for underfive children in Tigray region, Northern Ethiopia.

Methods: A cross-sectional study was conducted in Tigray region from December 2015 to July 2016 using a standard method developed by the World Health Organization and Health Action International (WHO/HAl). Data on the availability and price of 27 priority life-saving medicines were collected from 31 public and 10 private sectors. Availability and prices were expressed in percent and median price ratios (MPRs), respectively. Affordability was reported in terms of the daily wage of the lowest-paid unskilled government worker.

Results: The overall availability of priority life-saving drugs in this study was low (34.1\%). The average availabilities of all surveyed medicines in public and private sectors were 41.9 and $31.5 \%$, respectively. The overall availability of medicines for malaria was found to be poor with average values of $29.3 \%$ for artemisinin combination therapy tablet, 19.5\% for artesunate injection and $0 \%$ for rectal artesunate. Whereas, the availability of oral rehydration salt (ORS) and zinc sulphate dispersible tablets for the treatment of diarrhea was moderately high ( $90 \%$ for ORS and $82 \%$ for zinc sulphate). Medicines for pneumonia showed an overall percent availability in the range of $0 \%$ (ampicillin $250 \mathrm{mg}$ and $1 \mathrm{~g}$ powder for injection and oxygen medicinal gas) to 100\% (amoxicillin $500 \mathrm{mg}$ capsule). The MPRs of 12 lowest price generic medicines were 1.5 and 2.7 times higher than the international reference prices (IRPs) for the private and public sectors, respectively. About 30\% of priority life-saving medicines in the public sector and $50 \%$ of them in the private sector demanded above a single daily wages to purchase the standard treatment of the prevalent diseases of children.

Conclusions: The lower availability, high price and low affordability of lowest price generic priority life-saving medicines in public and private sectors reflect a failure to implement the health policy on priority life-saving medicines in the region.
\end{abstract}

Keywords: Priority life-saving medicines, Availability, Medicine Price, Affordability, Under-five children, Tigray Ethiopia

\footnotetext{
* Correspondence: abrha.solomon13@gmail.com

${ }^{1}$ Department of Pharmaceutics, School of Pharmacy, College of Health

Sciences, Mekelle University, Mekelle, Tigray, Ethiopia

Full list of author information is available at the end of the article
}

(c) The Author(s). 2018 Open Access This article is distributed under the terms of the Creative Commons Attribution 4.0 International License (http://creativecommons.org/licenses/by/4.0/), which permits unrestricted use, distribution, and reproduction in any medium, provided you give appropriate credit to the original author(s) and the source, provide a link to the Creative Commons license, and indicate if changes were made. The Creative Commons Public Domain Dedication waiver (http://creativecommons.org/publicdomain/zero/1.0/) applies to the data made available in this article, unless otherwise stated. 


\section{Introduction}

Being a critical improvement indicator of health, socioeconomic status and quality of life of a given population, there has been a global drive to improve the under-five children mortality rate during the past three decades [1]. To that end, over the past fifteen years, under-five global mortality rate has declined from 90.6 deaths per 1000 live births in 1990 to 42.5 in 2015 [2]. However, high rate remains in sub-Saharan Africa where one child in 12 dies before his or her fifth birthday - far higher than the average ratio of 1 in 147 in high-income countries [3]. In Ethiopia, children under-five mortality rate was reported to be 67 per 1000 live births in 2015 , with one in every fifteen children dying before their fifth birthday [4].

According to the United Nations (UN) commission on life-saving commodities for women and children, many of these deaths are due to conditions such as pneumonia, diarrhea and malaria, which could easily be prevented or treated by simple and affordable medicines administered before, during and immediately after birth [5]. For instance, of the 6.3 million under-five deaths in 2013, around 15, 11 and $7 \%$ of them were caused by pneumonia, diarrhea and malaria, respectively [6]. Yet, early diagnosis and treatment with simple antibiotics could avert as many as 600,000 of deaths in case of pneumonia whereas, improving access to ORS would save as many of 1.3 million children who are dying annually from diarrhea $[3,7]$.

In 2011, the WHO departments of essential medicines and health products and other stakeholders developed a list of priority life-saving medicines for women and children with the main aim of supporting countries to plummet maternal, newborn and child morbidity and mortality [8]. According to this document, priority life-saving medicines are medicines which have the potential to save lives of children that should be available in all health systems and at all times. Medicines for the management of pneumonia, diarrhea, malaria, neonatal sepsis, HIV, vitamin A deficiency, tuberculosis and pediatric palliative care have been included under priority life-saving medicines for children's health [8, 9].

Albeit some availability and affordability surveys [10, $11]$ have been conducted for children and adult on essential medicines, to the best of our knowledge, there was no a single previous study carried out to assess availability and affordability of the WHO recommended pediatric priority life-saving medicines in Ethiopia. Hence, the main aim of this study was to examine the availability and affordability of the life-saving priority medicines for children under five-years old in health facilities found in Tigray $\mathrm{Re}$ gion, Northern Ethiopia.

\section{Methods}

A cross-sectional study was conducted in Tigray region, Ethiopia from December 2015 to July 2016. Tigray region lies in the Northern part of Ethiopia. It borders Eritrea to the north and Sudan to the west, while in the east it shares a regional border with the Afar region and in the south-west with Amhara region. The region is sub-divided into 7 administrative zones and 52 districts with its capital in Mekelle. The region has a population of $4,314,456$, of which 630,862 are children under five years of age as per 2007 national census [12]. The health care system in the region comprises of tertiary and referral hospitals, zonal hospitals, district hospitals, health centers and health posts.

\section{Selection of health care facilities}

The medicine outlets were selected using the WHO/ HAI methodology, which has been validated to select a representative sample [13]. First, the main public hospital in the region, which is found in the capital city, Mekelle, was selected. Four public and five private medicine outlets (for example, hospital outpatient medicine outlets, dispensaries) which were in close proximity to the main public hospital were then randomly selected. Finally, additional private and public medicine outlets were chosen from other five survey areas within a 3-h drive from the main hospital. Accordingly, a total of 43 (10 public, 31 private and 2 nonprofit) medicine outlets were included in the study.

\section{Selection of medicines}

All the medicines surveyed (except paracetamol suppository) in our study were identified from the list of "Priority life-saving medicines for women and children" developed by WHO in 2012 [8]. WHO had chosen the medicines on this list according to the global burden of the diseases and the evidence of efficacy and safety for preventing or treating major causes of maternal, newborn and child mortality and morbidity. The recommended priority life-saving medicines for children under-five are artemisinin combination therapy, rectal artesunate and artesunate injectable for malaria; zinc sulphate dispersible tablets and ORS sachets for diarrhea; amoxicillin (capsule), ampicillin ceftriaxone and gentamycin (powder for injections) for treatment of pneumonia; and ampicillin and procaine benzyl penicillin (powder for injections) for neonatal sepsis.

A total of 27 medicines, all of which registered in the country, were studied. For each medicine in the survey, data on price and availability were collected for the originator brand (OB) and lowest priced generic (LPG) at each facility. However, only availability data were collected for drugs such as antimalaria medicines, vitamin A, magnesium sulfate, calcium gluconate and zinc since these medicines in public sector are free of charge to all. 
The OB product was defined as a single-brand product marketed by the originator pharmaceutical company whereas "LPG equivalents" were defined as the same product sold under the generic name with the lowest unit price at each medicine outlet at the time of data collection in the survey [13].

\section{Data collection and analysis}

Using a standard data collection format, data on availability and price were collected by well-trained pharmacists from March to May 2016. The principal investigator together with supervisors supervised the data collection process by checking all forms at the end of each day of the data collection. As part of the training workshop, a pilot test was conducted at retail medicine outlets, which could not form part of the survey sample but used to customize the data collection format. Data were coded, checked for completeness, consistency and accuracy for each medicine's unit price and analyzed using Microsoft ${ }^{\circ}$ Excel and Statistical Package for Social Scientists (SPSS ${ }^{\bullet} 20.0$ ) statistical software. Data on public and private sectors were analyzed separately whereas data on non-profit sectors were not amenable to analysis as there were only two non-profit sectors found during this study and in order to be considered for analysis the number of non-profit facilities should be four according to the WHO/HAI methodology [13].

The analyses of the study focused on three measures: medicine availability, prices and affordability. Medicine availability was reported as the percentage (\%) availability of an individual medicine at the surveyed outlets on the date of data collection [13]. Mean availability refers to the overall "basket" of medicines surveyed. To express the availability of medicines in the healthcare facilities, the following ranges were used [14]: $<30 \%, 30-49 \%, 50-$ $80 \%$, and $>80 \%$ for a very low, low, fairly high, and high availability, respectively. Prices were presented as MPRs, which are the ratios of the median local unit prices of medicines across facilities divided by their median IRPs [13]. The medicine prices obtained from the 2015 Drug Prices Guide issued by Management Science for Health (MSH) organization were adopted as the IRPs for core medicines [15]. MPR for a given medicine was calculated only if the medicines was available at a minimum of four facilities as per the WHO/HAI methodology and they were used as indicator to establish comparisons among countries. To calculate MPR, local median prices were converted to United States dollar (USD) using the exchange rate of commercial bank of Ethiopia at a buying rate of 21.8356 Ethiopian Birr (ETB) per 1 USD on the first day of data collection [16].

Notwithstanding the fact that there are no strict rules to interpret MPRs of medicines from medicine outlets, different studies [14, 17] reported using WHO/HAI methodology to explain the MPRs. Accordingly, if the MPR is twice of the IRP for a generic equivalent product, it can be considered as a cause for concern since the price is likely to be unaffordable [14]. In this study, the following MPR cut-off points: MPR $\leq 1.5$ for public hospital patient prices and MPR $\leq 2$ for retail pharmacies patient prices were used to represent acceptable local price ratios [18].

Affordability was estimated in this study as the number of daily wages of the lowest-paid unskilled government worker required to cover for the complete course of standard treatments of the selected diseases $[13,19,20]$. This was done by first computing the daily wage of the workers at the time of data collection, which was found to be 21.67 ETB per day (0.99 USD) [21]. The total costs of medicine for the complete duration of treatments of each disease were then determined and converted to the daily wages. Medicines that costed less than a day wage were considered affordable and those medicines with the cost of $\geq$ a day wage were considered unaffordable [22]. The total dose required to treat a particular health condition of children was calculated based on dose per kilogram $(\mathrm{kg})$ method using $14.5 \mathrm{~kg}$ as the average weight for a 5 -year-old child in Ethiopia [21, 23].

\section{Results}

Availability of the priority life-saving medicines for children under-five

The overall availability of priority life-saving drugs for children under-five in this study was $34.1 \%$. The average availabilities of all surveyed medicines in public and private sectors were 41.9 and $31.5 \%$, respectively. The availability of medicines was found to vary with the type of medicine and sector. For instance, the availability of all life-saving medications in public outlets was higher than private sector except for paracetamol $200 \mathrm{mg}$ suppository and ORS. Besides, the availability of artemisinin combination therapy for injection was almost thrice in the public sector compared to the private sector. Another important finding revealed in this study was the absence of morphine at any dose and dosage form, artesunate 50-200 mg suppository, paracetamol $200 \mathrm{mg}$ suppository, oxygen medicinal gas, ampicillin $250 \mathrm{mg}$ powder for injection and ampicillin $1 \mathrm{~g}$ powder for injection in both sectors (Fig. 1, Table 1). Moreover, there were no innovator brand medicines found in the public and private sectors.

Availability data on priority life-saving medicines used for the treatment of pneumonia, malaria and diarrhea are presented in Table 2. For the treatment of diarrhea, 90\% of the public and $97 \%$ of the private sectors had ORS, whereas zinc was available in $90 \%$ of the public health facilities and $80 \%$ of the private sectors. Anti-malarial formulations of artemisinin combination therapy tablet and 


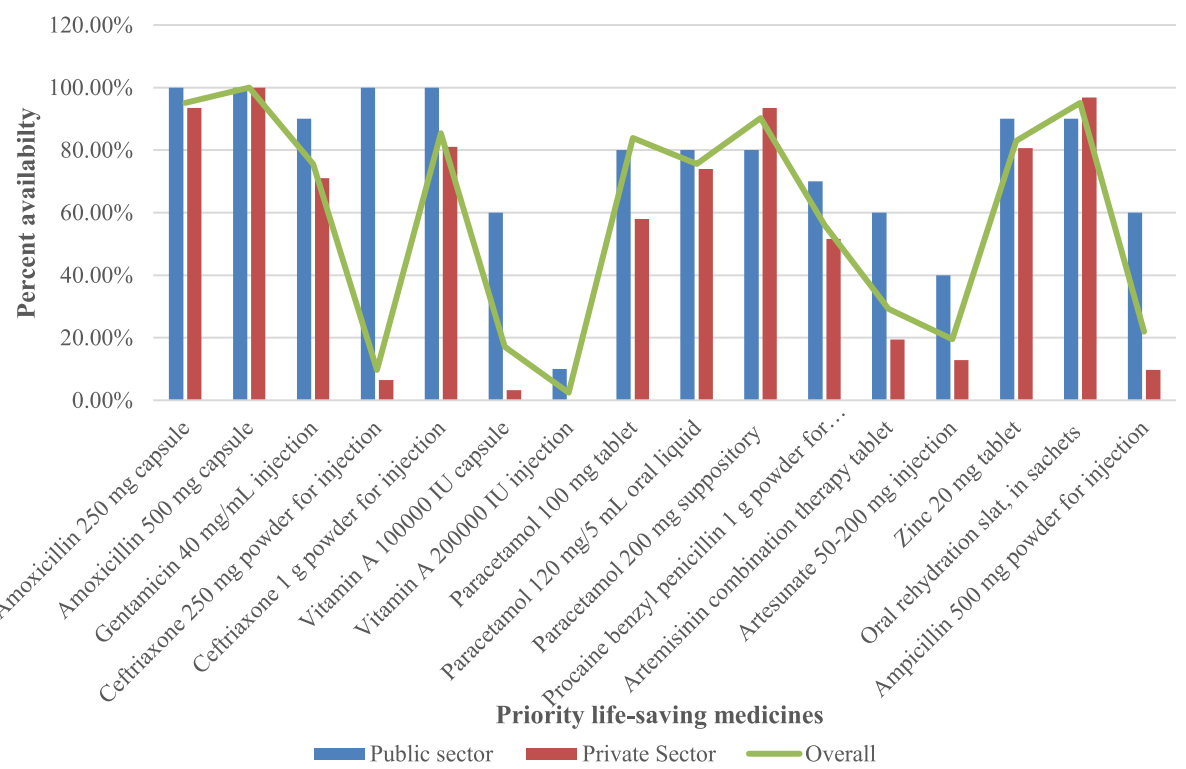

Fig. 1 Availability of the selected priority life-saving medicine. Blue colored graphs represent availability of medicines in public sectors; Red colored graphs represent availability of medicines in private sectors and Purple colored line shows the overall availability of surveyed medicines

artesunate injection were available in 60 and $40 \%$ of public and 20 and $13 \%$ of private sectors, respectively. Rectal artesunate was not available in all surveyed medicine outlets. Regarding the availability of medicines for pneumonia, amoxicillin, 250 and $500 \mathrm{mg}$ capsules were available in almost all sectors. Gentamycin injection was obtained in $90 \%$ of the public and $70 \%$ of the private sectors. Likewise, ceftriaxone $250 \mathrm{mg}$ powder for injection was present in all public sectors and $7 \%$ of the private sectors. Ampicillin $250 \mathrm{mg}$ and $1 \mathrm{~g}$ powder for injections were absent in all private and public sectors. However, ampicillin $500 \mathrm{mg}$ powder for injections was found in $60 \%$ of the public and $10 \%$ of the private sectors.

\section{Patient's price of priority life-saving medicines}

In general, the medicines in this survey were sold at higher prices than the IRP (Table 3). The MPRs of priority life-saving medicines for the public and private sectors ranged from (0.2-19.4) and (0.4-26.2), respectively. The median MPRs of 10 LPGs for public were 1.5 times the IRPs, while the median MPRs for LPGs in private were 2.7 times the IRPs. Moreover, only one medication from each sector was bought at lower prices than its IRP. On contrary, five medicines in public sector and seven medicines in private sector were more than twice of their IRPs (Table 3).

Among the priority life-saving medications, the lowest MPRs was observed for paracetamol $125 \mathrm{mg}$ suppository at both public (0.2) and private (0.4) sectors, as opposed to paracetamol oral suspension with MPRs of 19.4 in public and 26.2 in private sectors (Table 3). Besides, the highest price difference between the two sectors was noted in paracetamol suspension, which was $25 \%$ more in the private sector than the public sector.

\section{Treatment affordability for selected disease conditions with priority life-saving medicines}

The affordability of standard treatments for six different health conditions (10 medicines) is described in Table 4. About $30 \%$ of priority life-saving medicines in public sector and $50 \%$ of them in private sector required more than a single daily wage to purchase the standard treatment of the prevalent diseases of children. The wages required to purchase the standard treatment of LPGs for public and private sectors were in the ranges of 0.2 (ORS and paracetamol tablet) to 8.0 (penicillin G 1MIU) and 0.2 (paracetamol tablet) to 14.1(penicillin G 1MIU), respectively. Some treatments were very costly (Table 4 ).

The highest ratio between the private and public sectors was observed in ceftriaxone $1 \mathrm{~g}$ vial, which was used for the management of very sever pneumonia. Overall, when the affordabilities in public and private sectors were compared, priority life-saving medicines in private sectors were less affordable than public sectors (Table 4).

Figure 2 shows a stacked bar chart - used to compare the percentage that each value contributes to a total that compares the percentage of wages attributable to the private and public sector. Accordingly, the share contributed by the public sector was below $40 \%$ for all disease conditions, in which about one third of the wage for very severe pneumonia was attributable to the public sector. 
Table 1 Availability of priority life-saving medicines for children under-five in selected health sectors found in Northern Ethiopia, 2016

\begin{tabular}{|c|c|c|c|}
\hline \multirow[t]{2}{*}{ Name of the medicine } & \multicolumn{3}{|c|}{ Percentage (\%) of medicine outlets where medicine were found } \\
\hline & $\begin{array}{l}\text { Public sector } \\
\text { (10 outlets) }\end{array}$ & $\begin{array}{l}\text { Private sectors } \\
\text { (31 outlets) }\end{array}$ & $\begin{array}{l}\text { Overall } \\
\text { (41 outlets) }\end{array}$ \\
\hline Amoxicillin $250 \mathrm{mg}$ capsule & 100.0 & 93.5 & 95.1 \\
\hline Amoxicillin 500 mg capsule & 100.0 & 100.0 & 100.0 \\
\hline Gentamicin 40 mg/mL injection & 90.0 & 71.0 & 75.6 \\
\hline Ceftriaxone $250 \mathrm{mg}$ powder for injection & 100.0 & 6.5 & 9.8 \\
\hline Ceftriaxone $1 \mathrm{~g}$ powder for injection & 100.0 & 81.0 & 85.3 \\
\hline Morphine $100 \mathrm{mg}$ granules capsule & 0.0 & 0.0 & 0.0 \\
\hline Morphine $60 \mathrm{mg}$ granules capsule & 0.0 & 0.0 & 0.0 \\
\hline Morphine $30 \mathrm{mg}$ granules capsule & 0.0 & 0.0 & 0.0 \\
\hline Morphine 20 mg granules capsule & 0.0 & 0.0 & 0.0 \\
\hline Morphine 200 mg granules capsule & 0.0 & 0.0 & 0.0 \\
\hline Morphine $10 \mathrm{mg} / \mathrm{mL}$ injection & 0.0 & 0.0 & 0.0 \\
\hline Morphine $10 \mathrm{mg} / 5 \mathrm{~mL}$ oral liquid & 0.0 & 0.0 & 0.0 \\
\hline Vitamin A 100000 IU capsule & 60.0 & 3.2 & 17.1 \\
\hline Vitamin A 200000 IU injection & 10.0 & 0.0 & 2.4 \\
\hline Paracetamol $100 \mathrm{mg}$ tablet & 80.0 & 58.0 & 63.4 \\
\hline Paracetamol $120 \mathrm{mg} / 5 \mathrm{~mL}$ oral liquid & 80.0 & 74.0 & 75.6 \\
\hline Paracetamol 200 mg suppository & 80.0 & 93.5 & 90.2 \\
\hline Oxygen medicinal gas & 0.0 & 0.0 & 0.0 \\
\hline Procaine benzyl penicillin $1 \mathrm{~g}$ powder for injection & 70.0 & 51.6 & 56.1 \\
\hline Artemisinin combination therapy tablet & 60.0 & 19.4 & 29.3 \\
\hline Artesunate $50-200 \mathrm{mg}$ injection & 40.0 & 12.9 & 19.5 \\
\hline Artesunate $50-200$ mg suppository & 0.0 & 0.0 & 0.0 \\
\hline Zinc $20 \mathrm{mg}$ tablet & 90.0 & 80.6 & 82.9 \\
\hline ORS, in sachets & 90.0 & 96.8 & 95.1 \\
\hline Ampicillin 250 mg powder for injection & 0.0 & 0.0 & 0.0 \\
\hline Ampicillin 500 mg powder for injection & 60.0 & 9.7 & 22.0 \\
\hline Ampicillin $1 \mathrm{~g}$ powder for injection & 0.0 & 0.0 & 0.0 \\
\hline
\end{tabular}

\section{Discussions}

According to the findings of this study, the overall availability of priority life-saving medicines was found to be low. Due to variation in medicine pricing policy, methodology, types of prevalent disease, and medicine supply systems, it is difficult to make a comparative analysis of medicines availability. However, this result is in agreement with studies of the availability and affordability of essential medicines in Ethiopia [10] and elsewhere [18, 24, 25]. This calls for urgent action to address the availability of life-saving medications in the region.

The average availability of lowest priced medicines for children was $41.9 \%$ in the public and $31.5 \%$ in the private sectors. These findings are lower than a study done in Western part of Ethiopia [10] which reported 43\% for public and $42.8 \%$ for private sectors; comparable with reports of a study conducted in Guatemala [22] which found an availability $46 \%$ in public sector and $35 \%$ in private sector whereas higher than the study done by Wang et al. 2014 [18] in China, which reported availability of $27.3 \%$ for public sector and $20.6 \%$ for private sector. In agreement with the studies done elsewhere [18, 22], the present study showed that availability of medicines was higher in the public sector than in the private sector. However, considering the particular health service needing population, still, the figure in public sector was very low. The low availability of medicines at public hospitals could have direct implications on access, as patients are then persuaded to purchase these medicines from private pharmacies where quite often are sold for higher price. Private pharmacies most of the time carry fewer generic drugs than the public sectors; as a result, they may dispense 
Table 2 Availability of priority life-saving medicines used for the treatment of pneumonia, malaria and diarrhea for children underfive in selected health sectors found in Northern Ethiopia, 2016

\begin{tabular}{|c|c|c|c|c|}
\hline \multirow[t]{2}{*}{ Illness } & \multirow{2}{*}{$\begin{array}{l}\text { WHO recommended priority life-saving } \\
\text { medicine and their dosage forms }\end{array}$} & \multicolumn{3}{|c|}{ Percentage (\%) of medicine outlets where medicine was found } \\
\hline & & $\begin{array}{l}\text { Public sector } \\
\text { (10 outlets) }\end{array}$ & $\begin{array}{l}\text { Private sectors } \\
\text { (31 outlets) }\end{array}$ & $\begin{array}{l}\text { Overall } \\
\text { (41 outlets) }\end{array}$ \\
\hline \multirow[t]{9}{*}{ Pneumonia } & Amoxicillin $250 \mathrm{mg}$ capsule & 100.0 & 93.5 & 95.1 \\
\hline & Amoxicillin 500 mg capsule & 100.0 & 100.0 & 100.0 \\
\hline & Ampicillin $250 \mathrm{mg}$ powder for injection & 0.0 & 0.0 & 0.0 \\
\hline & Ampicillin 500 mg powder for injection & 60.0 & 9.7 & 22.0 \\
\hline & Ampicillin $1 \mathrm{~g}$ powder for injection & 0.0 & 0.0 & 0.0 \\
\hline & Ceftriaxone $250 \mathrm{mg}$ powder for injection & 100.0 & 6.5 & 9.8 \\
\hline & Ceftriaxone $1 \mathrm{~g}$ powder for injection & 100.0 & 81.0 & 85.4 \\
\hline & Gentamicin $40 \mathrm{mg} / \mathrm{mL}$ injection & 90.0 & 71.0 & 75.6 \\
\hline & Oxygen medicinal gas & 0.0 & 0.0 & 0.0 \\
\hline \multirow[t]{3}{*}{ Malaria } & Artemisinin combination therapy tablet & 60.0 & 19.4 & 29.3 \\
\hline & Artesunate $50-200 \mathrm{mg}$ injection & 40.0 & 12.9 & 19.5 \\
\hline & Artesunate 50-200 mg suppository & 0.0 & 0.0 & 0.0 \\
\hline \multirow[t]{2}{*}{ Diarrhea } & Zinc $20 \mathrm{mg}$ tablet & 90.0 & 80.6 & 82.9 \\
\hline & ORS, in sachets & 90.0 & 96.8 & 95.1 \\
\hline
\end{tabular}

more brand medicines. Obviously, brands are more costly than their generic equivalents that lead the patients to dig deep into their pockets to pay for medicines [26].

It was noted in this study that 11 medicines out of the 27surveyed priority life-saving medicines were absent in both private and public sectors. Particular concerning is the unavailability of rectal artesunate, ampicillin $(250 \mathrm{mg}$ and 1 g) injection and medicinal oxygen, which are the WHO recommended life-saving priority medicines for the treatment of malaria and pneumonia, even though lower respiratory tract infections including pneumonia and malaria are the foremost causes of death and disease burden among under-five children in Ethiopia [27, 28]. This finding is in line with a study done in Uganda [29]. According to some of the administration of the medicine outlets, the possible reason for the lower availability of ampicillin formulations in this study was due to the choice of ceftriaxone injection for many conditions over ampicillin. In addition to ampicillin and artesunate, all of the morphine dosage forms for palliative care and pain management and medicinal oxygen gas for pneumonia were absent in this study. The observed lack of availability of morphine could be partly tied to pethidine, which is the first line for pain management as compared to morphine, which is listed as the alternative treatments for pain management in the country's standard treatment guideline [19].

Table 3 Median price ratios of ten lowest priced medicines for children under-five years of age found in at least four medicine outlets in public and private sectors in Northern Ethiopia, 2016

\begin{tabular}{|c|c|c|}
\hline \multirow[t]{2}{*}{ Name of the Medicine } & \multicolumn{2}{|c|}{ Lowest priced medicines (MPR) } \\
\hline & $\begin{array}{l}\text { Public sector } \\
\text { (25th-75th percentile) }\end{array}$ & $\begin{array}{l}\text { Private sector } \\
\text { (25th-75th percentile) }\end{array}$ \\
\hline Amoxicillin $250 \mathrm{mg}$ capsule & $1.1(1.1-1.2)$ & $1.6(1.1-1.8)$ \\
\hline Amoxicillin 500 mg capsule & $1.5(1.4-1.5)$ & $1.8(1.5-1.8)$ \\
\hline Gentamicin 40 mg/mL ampoule & $1.1(0.9-1.7)$ & $2.0(1.3-2.9)$ \\
\hline Ceftriaxone $1 \mathrm{~g}$ vial & $1.2(1.2-1.2)$ & $2.7(2.2-2.7)$ \\
\hline Paracetamol $100 \mathrm{mg}$ tablet & $3.4(2.3-4.6)$ & $4.6(4.6-6.9)$ \\
\hline Paracetamol $120 \mathrm{mg} / 5 \mathrm{~mL}$ suspension & $19.4(17.9-23.4)$ & $26.2(21.8-32.7)$ \\
\hline Paracetamol 125 mg suppository & $0.2(0.2-0.2)$ & $0.4(0.4-0.4)$ \\
\hline Penicillin G 1 million IU vial & $1.5(1.3-1.6)$ & $2.7(2.5-3.1)$ \\
\hline ORS to make $1000 \mathrm{~mL}$ solution & $3.7(2.4-3.8)$ & $4.6(3.7-4.6)$ \\
\hline Ampicillin 500 mg Vial & $8.2(7.2-11.5)$ & $13.7(5.6-20.6)$ \\
\hline
\end{tabular}


Table 4 Number of days' wage required for the lowest paid Ethiopian government worker to purchase standard treatment for children under five of age in Northern Ethiopia, 2016

\begin{tabular}{|c|c|c|c|c|c|}
\hline & & & Days w & to pay for & ment \\
\hline & & & $\begin{array}{l}\text { Public } \\
\text { sector }\end{array}$ & $\begin{array}{l}\text { Private } \\
\text { sector }\end{array}$ & $\begin{array}{l}\text { Private to public } \\
\text { ratio }\end{array}$ \\
\hline $\begin{array}{l}\text { Non-severe } \\
\text { pneumonia }\end{array}$ & Ampicillin 500 mg vial & $\begin{array}{l}50 \mathrm{mg} / \mathrm{kg}^{*} 14.5 \mathrm{~kg} \text { QID IV for } \\
5 \text { days }=14,500 \mathrm{mg}=29 \text { vial }\end{array}$ & 4.8 & 8.1 & 1.7 \\
\hline Severe pneumonia & Amoxicillin 250 mg capsule & $\begin{array}{l}25 \mathrm{mg} / \mathrm{kg}^{*} 14.5 \mathrm{~kg} \text { BID P.O. for } \\
7 \text { days }=5075 \mathrm{mg}=21 \mathrm{cap}\end{array}$ & 0.5 & 0.7 & 1.4 \\
\hline Severe pneumonia & Amoxicillin 500 mg capsule & $\begin{array}{l}25 \mathrm{mg} / \mathrm{kg}^{*} 14.5 \mathrm{~kg} \text { BID P.O. for } \\
7 \text { days }=5075 \mathrm{mg}=11 \text { cap }\end{array}$ & 0.5 & 0.6 & 1.2 \\
\hline Severe pneumonia & Penicillin G 1000,000 IU vial & $\begin{array}{l}50,000 \text { units } / \mathrm{kg}^{*} 14.5 \mathrm{~kg} \text { IV every } \\
4 \mathrm{~h} \text { for at least } 3 \text { days }=13.03 \\
\text { millions of IU }=14 \text { vial }\end{array}$ & 3.9 & 6.8 & 1.7 \\
\hline $\begin{array}{l}\text { Very severe } \\
\text { pneumonia }\end{array}$ & Gentamicin $80 \mathrm{mg} / 2 \mathrm{~mL}$ ampoule & $\begin{array}{l}7.5 \mathrm{mg} / \mathrm{kg}^{*} 14.5 \mathrm{~kg} \text { IV daily for } \\
5 \text { days }=14 \mathrm{ml} 7 \text { ampoule }\end{array}$ & 0.6 & 1.1 & 1.8 \\
\hline $\begin{array}{l}\text { Very severe } \\
\text { pneumonia }\end{array}$ & Ceftiaxone $1 \mathrm{~g}$ vial & $\begin{array}{l}80 \mathrm{mg} / \mathrm{kg}^{*} 14.5 \mathrm{~kg} \text { IV daily for } \\
10 \text { days }=11.6 \mathrm{~g} 12 \text { vial }\end{array}$ & 6.1 & 13.9 & 2.3 \\
\hline Neonatal sepsis & $\begin{array}{l}\text { Gentamicin } 80 \text { mg/2 mL (40/mL) } \\
\text { ampoule }\end{array}$ & $\begin{array}{l}5 \mathrm{mg} / \mathrm{kg}^{*} 14.5 \mathrm{~kg} \text { IV daily for } \\
10 \text { days }=20 \mathrm{ml} 10 \text { ampoule }\end{array}$ & 0.9 & 1.6 & 1.8 \\
\hline Neonatal sepsis & Penicillin G 1000,000 IU vial & $\begin{array}{l}50,000 \text { units } / \mathrm{kg}^{*} 14.5 \mathrm{~kg} \text { IV QID } \\
\text { for } 10 \text { days }=29 \text { millions } \\
\text { of } I U=29 \text { vial }\end{array}$ & 8.0 & 14.1 & 1.8 \\
\hline Dehydration & Oral rehydration salt, in sachets & $75 \mathrm{ml} / \mathrm{kg}^{*} 14.5 \mathrm{~kg}=1087.5 \mathrm{ml}$ & 0.2 & 0.3 & 1.5 \\
\hline Pain/inflammation & Paracetamol $125 \mathrm{mg} / 5 \mathrm{~mL}$ suspension & $\begin{array}{l}5 \text { years old child: P.O. } \\
15 \mathrm{mg} / \mathrm{kg}^{*} 14.5 \mathrm{~kg}^{*} 4^{*} 3=104.4 \mathrm{ml}\end{array}$ & 0.4 & 0.6 & 1.5 \\
\hline Pain/inflammation & Paracetamol 125 mg suppository & $\begin{array}{l}5 \text { years old child: rectal } \\
15 \mathrm{mg} / \mathrm{kg}^{*} 14.5 \mathrm{~kg}^{*} 4^{*} 3= \\
20.88=21 \text { suppositories }\end{array}$ & 1.0 & 1.9 & 1.9 \\
\hline Pain/inflammation & Paracetamol $100 \mathrm{mg}$ tablet & $\begin{array}{l}5 \text { years old child: } P . O \text {. } \\
15 \mathrm{mg} / \mathrm{kg}^{*} 14.5 \mathrm{~kg}^{*} 4^{*} 3= \\
26.1=27 \mathrm{tabs}\end{array}$ & 0.2 & 0.2 & 1.0 \\
\hline
\end{tabular}

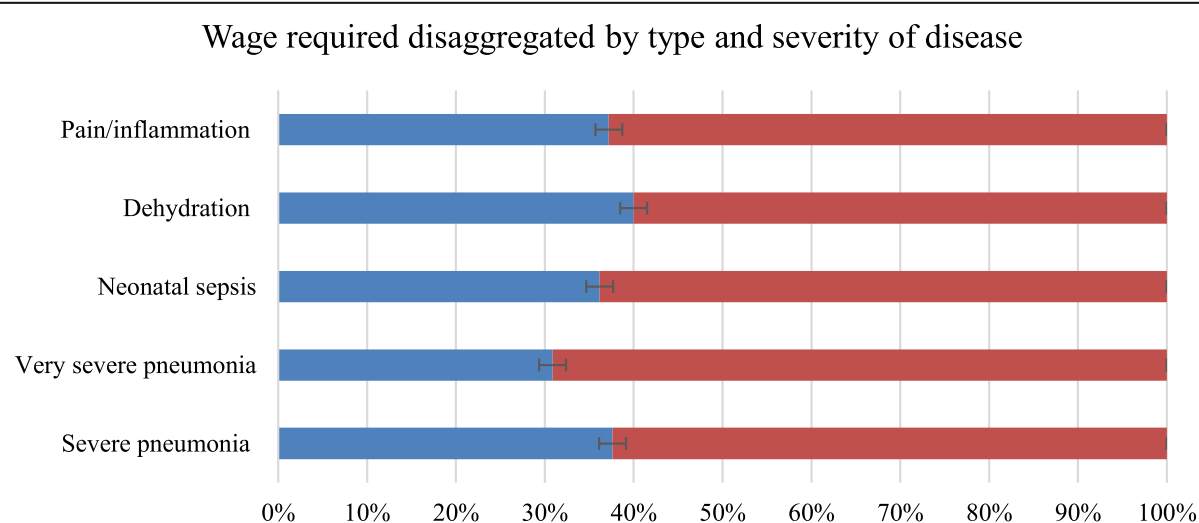

- Days wages to pay for treatment in public sector $\quad$ Days wages to pay for treatment in private sector

Fig. 2 Number of days' wage required for the lowest paid Ethiopian government worker. Blue colored portions of the graphs represent daily wages required to cover the total costs for full course of therapy of the selected diseases in public sectors. Red colored portions of the graphs represent daily wages required to cover the total costs for full course of therapy of the selected diseases in public sectors. Legend: The horizontal bar that intersects both sectors denotes an error bar 
Despite its known clinical benefit and proven effectiveness in reducing mortality from pneumonia [30], medicinal oxygen was found to be absent in almost all sectors surveyed in this study. This finding is very disquieting because oxygen is perhaps the only drug with no alternative agent [31]. Oxygen therapy should therefore be available for children care in every sector especially for the management of pneumonia as it is the leading cause of death in children under-5 worldwide.

The prices of priority life-saving medicines in this study were relatively higher as compared to IRPs. There was a variation in prices for medicines in public and private sectors. In the public sector, they were sold at 1.5 times their IRP and 2.7 times their IRP in the private sector. Similar findings were reported in another local study [10] as well as studies in South America [22] and Asia [18]. The reason for the lower price of medicines in public sectors could be the effort made by the Ethiopian government to reduce drug prices over the last decade by designing various mix of policies to regulate the price on pharmaceutical products so that there would not be higher price mark-ups in public sectors.

Despite the fact that it is difficult to assess true affordability, treatments costing one day's wage or less are generally considered affordable. Assessed accordingly, in the current study, about $30 \%$ of medicines in public sector and $50 \%$ of them in private sector were unaffordable. This shows that a significant segment of the population would not be able to pay for their medicines. Even medicines like amoxicillin, paracetamol tablet and gentamicin which were seemed affordable for the lowest government wage could be out-of-reach for a substantial number of people in Ethiopia because around 30\% of the population in the country is living below the international poverty line (defined as an income of less than $\$ 1.9 /$ day) [32]. These costs do not even include the costs of consultation and diagnostic tests; hence, families who need medicines for more than one child may be confronted with more costs and extra days' wages. These findings are consistent with other studies [10, 22, 33, 34] done on the affordability of essential medicines for children.

Eventhough Ethiopia achieved millennium development goal for reducing child mortality, the findings from this study advocate that availability and affordability of priority life-saving medicines for children is still low. High medicine prices and low incomes are considered as the notable barriers to the affordability of treatments particularly in developing countries. Country or regional health authorities must therefore improve the availability of more affordable generic priority life-saving medicines in the public sector by monitoring efficiency of the public sector procurement system as well as encouraging local pharmaceutical manufacturing. Besides, regulatory authorities need to provide a regulatory and enforcement mechanism in which cheaper alternative medicines would be more often prescribed, dispensed and used than newer, more expensive medicines. In general, this study suggests the regional priority life-saving medicine policy to be established, developed and enforced at both public and private sectors to ensure availability and affordability to basic health services, particularly for the poor.

This study has a certain limitation. It did not explore the factors affecting the availability and utilization of the priority medicines for children in public and private health facilities in Tigray region. Undertaking a more in-depth study to explore the underlying factors is needed. The study did not survey medicine procurement prices at wholesales due to logistical constraints. Percentage of medicines availability at the time of data collection may not be the same all year long. Since the study was predominantly based on WHO/HAI methodology, the concerns pertaining to the representativeness of the selected medicine outlets still can arise. Moreover, patient charges in all sectors were compared with IRPs, which do not consider freight and other margins and markups. This may affect the validity of the price comparison.

\section{Conclusions}

This study divulges that the availability and affordability of life-saving priority medicines for children under-five were limited in health facilities of the region in spite of the WHO emphasis. This result calls for urgent action to address the availability of life-saving medications in the region. An integration of these life-saving medicines into the logistic and essential drug list of the health facilities remains pertinent to increase their availability and affordability.

\section{Abbreviations}

BID: Two times a day; g: gram; IRP(s): International Reference Unit Price(s); IU: International Unit; Kg: kilogram; LPG: Lowest Priced Generic; mg: milligram; mL: Milliliter; MPR(s): Median Price Ratios(s);

MSH: Management Science for Health; OB: Originator Brand; ORS: Oral Rehydration Salts; PO: per oral; QID: Four times a day; WHO/HAl: World Health Organization/Health Action International

\section{Acknowledgements}

The authors would like to acknowledge all health care professionals participated in this study.

\section{Funding}

This study was financially supported by Mekelle University. The author SA received the funding. The funder had no role in study design, data collection and analysis, decision to publish, or preparation of the manuscript.

\section{Availability of data and materials}

All relevant data are within the paper. However, should you need additional information, the corresponding author could be contacted through the following email address abrha.solomon13@gmail.com

\section{Authors' contributions}

Conceived and designed the experiments: SA ET AW. Performed the experiments: SA ET TMA FM WM BM AW. Analyzed the data: SA TMA FM. Wrote the paper: SA ET TMA FM WM BM SG AW. All authors have read and approved the final manuscript. 


\section{Ethics approval and consent to participate}

The study was approved by Mekelle University Health Sciences College Ethical Review Committee (MUHSCERC). After approval of ethical issues, official letters of permission were obtained from Tigray Regional Health Bureau for each health care facilities. The permission letters were distributed to administrators of the respective medicine outlets and permission was obtained from them to conduct the study. The aim of the study was then clarified to the study participants, confidentiality was ensured and written consent was obtained prior to data collection.

\section{Consent for publication}

Not applicable.

\section{Competing interests}

The authors declare that they have no competing interests.

\section{Publisher's Note}

Springer Nature remains neutral with regard to jurisdictional claims in published maps and institutional affiliations.

\section{Author details}

'Department of Pharmaceutics, School of Pharmacy, College of Health Sciences, Mekelle University, Mekelle, Tigray, Ethiopia. ${ }^{2}$ Clinical Pharmacy Unit, School of Pharmacy, College of Health Sciences, Mekelle University, Mekelle, Tigray, Ethiopia. ${ }^{3}$ Department of Pharmacology and Toxicology, School of Pharmacy, College of Health Sciences, Mekelle University, Mekelle, Tigray, Ethiopia. ${ }^{4}$ Department of Pharmacy, College of Health Sciences, Bahir Dar University, Bahir Dar, Amhara, Ethiopia.

\section{Received: 16 October 2017 Accepted: 20 November 2018}

\section{Published online: 29 November 2018}

\section{References}

1. United Nations, Department of Economic and Social Affairs, Population Division. World Mortality Report 2015: Mortality Data Inventory 2015 (POP/ DB/MORT/2015). Available online at: http://www.un.org/en/development/ desa/population/theme/mortality. Accessed 28 May 2017.

2. You D, Hug L, Ejdemyr S, Idele P, Hogan D, Mathers C, et al. Global, regional, and national levels and trends in under-5 mortality between 1990 and 2015, with scenario-based projections to 2030: a systematic analysis by the UN inter-agency Group for Child Mortality Estimation. Lancet. 2015;386:2275-86.

3. WHO. United Nations Children's Fund, The World Bank. Population Division. Levels \& Trends in Child Mortality Report 2015 Estimates. Available at: http:// www.who.int/maternal_child_adolescent/documents/levels_trends_child_ mortality_2015/en/. Accessed 22 May 2017.

4. Central Statistical Agency (CSA) [Ethiopia] and ICF. Ethiopia Demographic and Health Survey. In: Key indicators report. Addis Ababa, Ethiopia, and Rockville. USA: Maryland; 2016. p. 2016.

5. WHO. UN Commission on Life-Saving Commodities for Women and Children. 2012. http://www.unfpa.org/publications/un-commission-lifesaving-commodities-women-and-children. Accessed 21 June 2017.

6. WHO. World health Statistics, vol. 2015. apps.who.int/iris/bitstream/10665/ 170250/1/9789240694439_eng.pdf. Accessed 14 Aug 2017.

7. WHO. Top 30 medicines to save mothers and children 2011. http://www. who.int/mediacentre/news/notes/2011/mother_child_medicine_20110321/ en. Accessed 08 May 2017.

8. WHO. Priority lifesaving medicines for mothers and children. Geneva; 2012 http://apps.who.int/iris/bitstream/handle/10665/75154/WHOEMPMAR2012. 1eng.pdf;isessionid=933975DDAFCCDF3FA104F2390E727819? sequence $=1$. Accessed 21 Nov 2018.

9. Hill K, You D, Inoue M, Oestergaard MZ. On behalf of the United Nations Inter-agency Group for Child Mortality Estimation and its Technical Advisory Group. 2012. Accelerating Progress in reducing global child mortality, 19902010. Forthcomings.

10. Sado E, Suf A. Availability and affordability of essential medicines for children in the Western part of Ethiopia: implication for access. BMC Pediatr. 2016:16:40.

11. Abiye Z, Tesfaye A, Hawaze S. Barriers to access: availability and affordability of essential drugs in a retail outlet of a public health center in South Western Ethiopia. J App Pharm Sci. 2013;10:1-5.
12. CSA. Population and Housing census report-Tigray Region 2007. http:// catalog.ihsn.org/index.php/catalog/3583. Accessed 01 June 2017.

13. WHO. Measuring medicine prices, availability, affordability and price components.2008. 2ND EDITION. WHO/PSM/PAR/2008.3.

14. Gelders S, Ewen M, Noguchi N, Laing R. Price, availability and affordability: an international comparison of chronic disease medicines. 2006. http://apps.who. int/iris/bitstream/10665/116493/1/dsa560.pdf. Accessed 18 Jan 2016.

15. Management Sciences for Health. International Drug Price Indicator Guide. 2014 edition.

16. Commercial Bank of Ethiopia. http://www.combanketh.et/More/ CurrencyRate.aspx. Accessed 18 Jan 2016.

17. Xi X, Li W, Li J, Zhu X, Fu C, Wei X, Chu S. A survey of the availability, prices and affordability of essential medicines in Jiangsu Province, China. BMC Health Serv Res. 2015;15:345.

18. Wang $X$, Fang $Y$, Yang $S$, Jiang $M$, Yan $K$, et al. Access to pediatric essential medicines: a survey of prices, availability, affordability and price components in Shaanxi Province, China. PLoS One. 2014;9:e90365. https://doi.org/10. 1371/journal.pone.0090365

19. Federal Democratic Republic of Ethiopia. Food. Medicine and healthcare administration and control Authority of Ethiopia. In: Standard treatment guidelines for general hospital 3rd ed; 2014.

20. Federal Democratic Republic of Ethiopia. Ministry of Health. Pediatric hospital care pocket book of guidelines for the Management of Common Illnesses in hospitals. In: 1st edition; 2010.

21. CSA. Ethiopia Demographic and Health Survey. Addis Ababa. Ethiopia: Central statistical Agency of Ethiopia; 2011. p. 2012.

22. Anson A, Ramay B, Esparza A, Bero L. Availability, prices and affordability of the World Health Organization's essential medicines for children in Guatemala. Glob Health. 2012;8:22.

23. WHO. Child growth standards. https://www.who.int/childgrouth/standards/ weight for age/en/. Accessed 22 June 2016.

24. Gitanjali B, Manikandan S. Availability of five essential medicines for children in public health facilities in India: a snapshot survey. J Pharmacol Pharmacother. 2011;2:95-9.

25. Balasubramaniam R, Beneragama BV, Sri RS. A national survey of availability of key essential medicines for children in Sri Lanka. Ceylon Med J. 2011:56:101-7.

26. Babar ZUD, Ibrahim MIM, Singh H, Bukahri NI, Creese A. Evaluating drug prices, availability, affordability, and price components: implications for access to drugs in Malaysia. PLoS Med. 2007;4(3):e82. https://doi.org/10. 1371/journal.pmed.0040082.

27. UN Human Rights Council. Study by the World Health Organization on mortality among children under five years of age as a human rights concern Available at: http://www.refworld.org/docid/523061aa4.html. Accessed 24 Mar 2017

28. Global Burden of Disease Mortality Collaboration. Global, regional, and national under-5 mortality, adult mortality, age-specific mortality, and life expectancy, 1970-2016: a systematic analysis for the global burden of disease study 2016. Lancet. 2017;390(10100):1084-150.

29. Xavier Nsabagasani X, Ogwal-Okeng J, Mbonye A, Ssengooba F, Muhumuza S, Hansen EH. Availability and utilization of the WHO recommended priority lifesaving medicines for under five-year old children in public health facilities in Uganda: a cross-sectional survey. J Pharm Policy Pract. 2015;8:18.

30. WHO. Report of WHO informal consultation on clinical use of oxygen. Geneva. 2003. Available from: http://www.who.int/surgery/collaborations/Oxygen_ Meeting_Report_Geneva_2003.pdf. Accessed 26 Sept 2017.

31. Duke T, Graham SM, Cherian MN, Ginsburg AS, English M, Howie S, Peel D, Enarson PM, Wilson $1 \mathrm{H}$, Were W. Oxygen is an essential medicine: a call for international action. Int J Tuberc Lung Dis. 2010;14(11):1362-8.

32. World Bank Group Ethiopia Poverty Assessment 2014. Washington, DC. (c) World Bank.2015. https://openknowledge.worldbank.org/handle/10986/ 21323 License: CC BY 3.0 IGO.

33. Chahal HS, St Fort N, Bero L. Availability, prices and affordability of essential medicines in Haiti. J Glob Health. 2013;3(020405) http://www. pubmedcentral.nih.gov/articlerender.fcgi?artid=3868824\&tool= pmcentrez\&rendertype. Accessed 20 June 2016.

34. Shafiq Y, Shaikh BT, Kumar R. Availability and affordability of essential medicines: exploring the health seeking behaviors and health service utilization for children under-5 years living in squatter settlement of Karachi. Pakistan J Ayub Med Coll. 2011;23:132-8. 